\title{
Estatísticas, grupos de risco e sinais de um comportamento suicida
}

\author{
Statistics, risk groups and signs of suicide behavior \\ Estadísticas, grupos de riesgo y señales de comportamiento suicídio \\ Camila Mazza da SILVA ${ }^{1}$ \\ Victor COLUCCI NETO ${ }^{2}$
}

IMembro do GEDTRAB - FDRP/USP, Grupo de Estudos em Direito do Trabalho da Faculdade de Direito de Ribeirão Preto - SP, Universidade de São Paulo FDRP/USP Pós-Graduada e Especializada em Direito Material e Processual do Trabalho pela Faculdade de Direito da Universidade Laudo de Camargo - Universidade de Ribeirão Preto (UNAERP) - SP, Brasil. Pós-Graduada em Direito do Trabalho pela Uniasselvi - SC, Brasil. Graduação em Direito pela Faculdades COC de Ribeirão Preto - SP, Brasil ${ }^{2}$ Mestrando - Programa de Pós-Graduação em Direito e Desenvolvimento da Faculdade de Direito de Ribeirão Preto - SP, Universidade de São Paulo FDRP/USP Pós-Graduação Lato Sensu em Direito Processual Civil pela UNAERP - Universidade de Ribeirão Preto - SP, Brasil Graduação em Direito pela Universidade Paulista -UNIP campus de Ribeirão Preto - SP, Brasil

\section{Resumo}

O presente artigo tem por finalidade trazer à baila algumas questões relacionadas ao suicídio. Para tanto serão abordados aspectos relacionados aos grupos de risco, nos quais estão inseridos os indivíduos com históricos de tentativas de suicídio ou autoagressão anterior, como a automutilação; os vitimizados por bullying; situações atuais ou anteriores de violência intra ou extrafamiliar; histórico de abuso sexual; suicídio na família; baixa autoestima; usuários de álcool ou outras drogas; discriminação social, depressão, dentre outros. Além disso, pretende-se elucidar quais seriam os comportamentos e sinais suicidas, identificando-os e abordando-os sobretudo com relação às crianças e aos adolescentes. Para tanto, foram selecionadas publicações em periódicos referenciados nas fontes de dados do Google Acadêmico, Pubmed e Periódicos Capes com as palavras chaves relacionadas ao tema desse trabalho suicídio, grupos de risco, autoestima, criança e adolescente sendo selecionadas publicações até 2020.

Descritores: Suicídio; Grupos de Risco; Autoestima; Criança; Adolescente.

\section{Abstract}

The purpose of this article is to bring up some issues related to suicide. To this end, aspects related to risk groups will be addressed, in which individuals with a history of suicide attempts or previous self-harm are inserted, such as self-mutilation; those victimized by bullying; current or previous situations of intra or extra-family violence; history of sexual abuse; suicide in the family; low self-concept; alcohol or other drug users; social discrimination, depression, among others. In addition, it is intended to elucidate what suicidal behaviors and signs would be, identifying and addressing them especially with regard to children and adolescents. For this purpose, publications were selected in journals referenced in the data sources of Google Scholar, Pubmed and Periódicos Capes with the keywords related to the theme of this suicide, risk groups, self concept, child and adolescent, and publications until 2020 were selected.

Descriptors: Suicide; Risk Groups; Self Concept; Child; Adolescent.

\section{Resumen}

El propósito de este artículo es plantear algunos problemas relacionados con el suicidio. Con este fin, se abordarán aspectos relacionados con los grupos de riesgo, en los que se insertan individuos con antecedentes de intentos de suicidio o autolesiones previas, como la automutilación; aquellos víctimas de acoso escolar; situaciones actuales o anteriores de violencia dentro y fuera da familia; historia de abuso sexual; suicidio en la familia; bajo autoimagen; usuarios de alcohol u otras drogas; discriminación social, depresión, entre otros. Además, se pretende dilucidar cuáles serían los comportamientos y signos suicidas, identificándolos y dirigiéndolos especialmente con respecto a los niños y adolescentes. Para este fin, se seleccionaron publicaciones en revistas a las que se hace referencia en las fuentes de datos de Google Scholar, Pubmed y Periódicos Capes con las palabras clave relacionadas con el tema de este trabajo suicida, grupos de riesgo, autoestima, niños y adolescentes, y se seleccionaron publicaciones hasta 2020.

Descriptores: Suicidio; Grupos de Riesgo; Autoimagen; Niño; Adolescente.

INTRODUÇÃO

\section{Em 1897 o sociólogo francês Émile} Durkheim publicou uma obra - escrita por ele mesmo - fundamental para o estudo em questão, denominado "O Suicídio", provocando um deslocamento do foco do suicídio do indivíduo para a sociedade, dividiu o suicídio em três tipos, a saber: suicídio egoísta, suicídio anômico e suicídio altruísta ${ }^{1}$.

O primeiro tipo, o suicídio egoísta, é aquele em que o indivíduo se afirma em demasia em relação ao coletivo, ou seja, as buscas de ordem pessoal do indivíduo são maiores que os objetivos da sociedade a qual está inserido. Esse quadro pode ser agravado em casos de descrença com as instituições públicas e com a sociedade como um todo. Para esse tipo, o indivíduo coloca as suas questões e anseios particulares como sua meta de vida acima de todas as outras, e, as frustações nesse campo podem acarretar a falta de sentido para a vida, não tendo razões para viver. No segundo, no suicídio anômico, há uma anomia social, ou seja, há anomia de regras na sociedade ou até mesmo uma crise moral, capaz de gerar uma descrença nas instituições públicas. Referido fato pode ser gerado por uma mudança social, como uma grave crise econômica, em que há uma grande desregulação das normas da sociedade. Esse tipo de suicídio tem a tendência de ocorrer em países com melhores condições econômicas.

A última modalidade, o suicídio altruísta, se caracteriza como sendo aquele no qual o indivíduo assume que sua vida tem um valor menor em detrimento de um grupo ao qual pertence ou um ideal pelo qual seja defensor. Como exemplo, podem-se citar os kamikases japoneses ou os terroristas que colidiram com as torres gêmeas em 2001.

$\mathrm{Na}$ visão de Durkheim as duas primeiras modalidades de suicídio seriam as mais comuns, quais sejam: os egoístas e os anômicos. E quais seriam as estatísticas do suicídio no mundo e no Brasil? Todos os suicídios são devidamente catalogados?

\section{REVISÃO DA LITERATURA E DISCUSSÃO}

O suicídio ocorre no mundo todo, não sendo um privilégio local. Todavia, em algumas regiões o fenômeno é mais intenso; dados estatísticos demonstram as posições geográficas de maior ocorrência. Cerca de 800.000 pessoas morrem por ano devido ao suicídio: uma pessoa a cada 40 segundos ${ }^{2}$. 
O suicídio é um fenômeno cuja ocorrência e extensão é global e pode ocorrer durante toda a vida útil. Há intervenções eficazes e baseadas em evidências as quais podem ser implementadas nos níveis populacional, subpopular e individual para evitar suicídio e possíveis tentativas de suicídio. Existem indicações de que, para cada adulto que morreu por suicídio, pode ter havido mais de 20 outros tentando se suicidar ${ }^{2}$. A Figura 1 indica a ocorrência dos suicídios em 2016 a cada 100.000 habitantes, de ambos os sexos ${ }^{3}$.

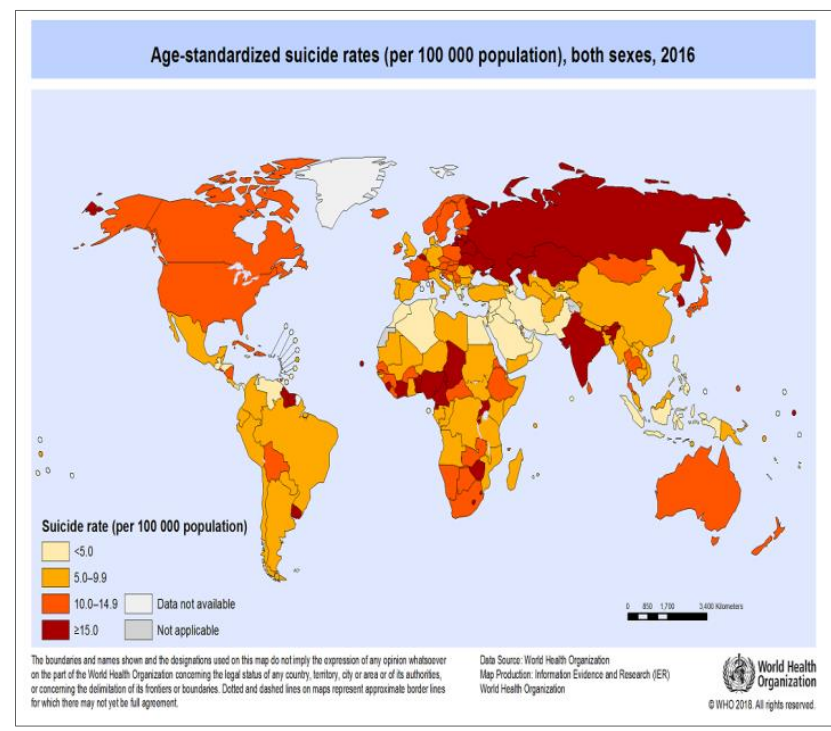

Figura 1: Idade-taxas padronizadas de suicídio (por 100.000 habitantes), de ambos os sexos, 2016. (Fonte: World Health Organization) ${ }^{3}$.

Já na Figura 2 abaixo pode-se observar que o suicídio ocorre durante toda a vida útil e é a segunda principal causa de morte entre pessoas de 15 a 29 anos no mundo. Tais dados foram extraídos de levantamento realizado no ano de 2016 pela Organização Mundial da Saúde (OMS) ${ }^{2}$.

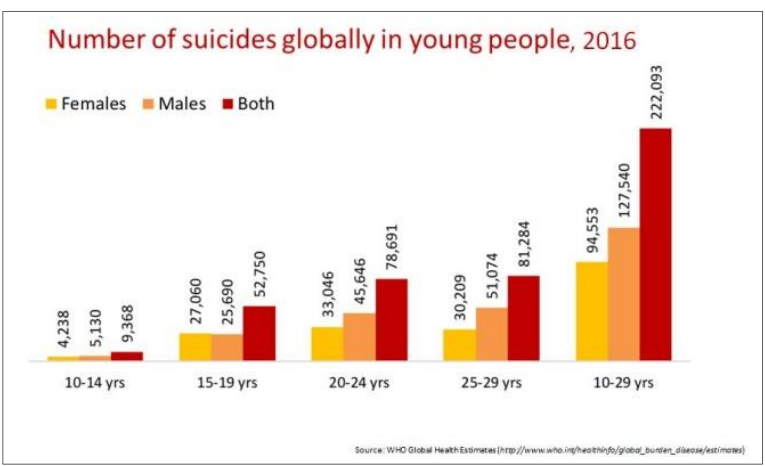

Figura 2: Número de suicídios global entre pessoas entre 10 a 29 anos. (Fonte: World Health Organization) ${ }^{2}$.

$\mathrm{Na}$ Tabela 3 podem ser observados os índices de suicídio de acordo com a idade e nível de renda. Observa-se que a taxa de suicídio no ano de 2016 foi menor em países da alta de renda em relação aos países de baixa e média renda, sendo a percentagem nestes últimos em torno de $79 \%$ e a sua maior ocorrência entre as idades de 20 e 35 anos. Destacase que o suicídio foi responsável por $1,4 \%$ de todas as mortes no mundo, tornando-se a $18^{\mathrm{a}}$ principal causa de morte em $2016^{2}$.

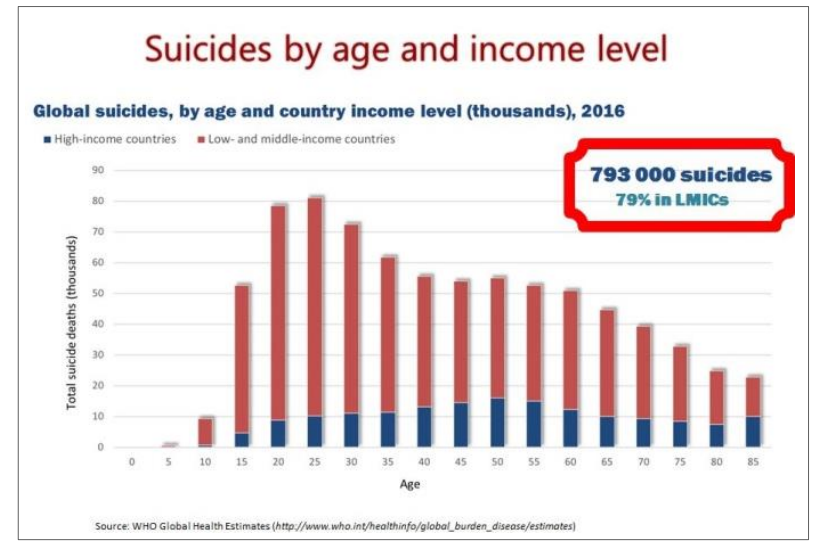

Figura 3: Índices de suicídio de acordo com a idade e nível de renda. (Fonte: World Health Organization ${ }^{3}$ )

No Brasil a situação não é diferente, o país está situado no oitavo lugar do mundo segundo a OMS, sendo mais de 11,8 mil suicídios catalogados em 2012. A grande preocupação dos especialistas é que esse comportamento vem atingindo um número cada vez maior de pessoas, já que em um período de 10 anos o número de suicídios cresceu cerca de $10 \%$ no país. Os dados da Organização Mundial de Saúde (OMS) revelam que o suicídio tornou uma epidemia de proporções globais, matando mais de $800 \mathrm{mil}$ pessoas por ano e, conforme exposto na Figura 4, $75 \%$ são catalogados em países emergentes e pobres ${ }^{4}$.

Especialistas no assunto criticam o modo como essa temática é tratado no Brasil, pois para eles as questões envolvendo suicídio são negligenciadas, não há políticas públicas capazes de atender a demanda, por vezes sendo um assunto incômodo, que preferem "varrer para debaixo do tapete", ao invés de tentar solucionar ${ }^{4}$. A grande questão envolvendo o tema é que falta estratégia, pois enquanto que em países desenvolvidos o número de pessoas que tiraram a própria vida começou a diminuir, o mesmo não se repetiu em nações em desenvolvimento, como no Brasil. Tal fato estaria ligado a ausências de estratégias nacionais que sejam capazes de debater sobre o assunto e de propor melhorias no sistema de saúde pública, para o fim de diminuir as dificuldades da população ao acesso de tratamento via governo ${ }^{4}$. Observa-se a colocação do Brasil, em $8^{\circ}$ lugar. Porém, a questão que segue é a seguinte: Esses números representariam a totalidade de suicídios ocorridos?

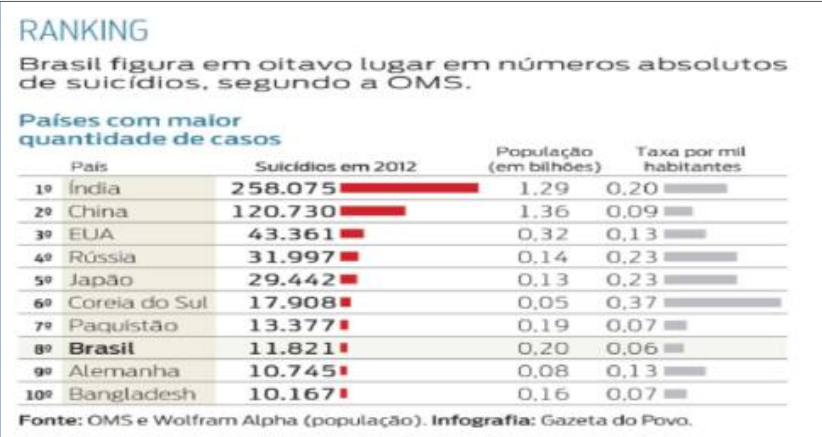

Figura 4: Ranking dos países com maior número de suicídio. (Fonte: GAZETA DO POVO, 2014 ${ }^{4}$ ) 


\section{- Todos os suicídios são notificados?}

Cumpre chamar a atenção para a questão das subnotificações dos casos de suicídio e autolesão. No Brasil esses dados são resultado de uma síntese de informações constantes nos atestados de óbito, compiladas em um Sistema de Informação de Mortalidade (SIM), que é mantido pelo Ministério da Saúde. O Instituto Brasileiro de Geografia e Estatística (IBGE) estima que 9,5\% dos óbitos ocorridos pelo suicídio não possuem registro ${ }^{5}$.

Em 2011 o Brasil ficou entre os dez países que registraram os maiores números absolutos de suicídios, com 9.852 mortes, sendo que o coeficiente médio para o período 2004-2010 foi de 5,7\%. Esse índice aumentou $29,5 \%$ nas duas últimas décadas e é mais elevado em homens, idosos, indígenas e em cidades de pequeno e de médio porte populacional ${ }^{6}$.

Importante destacar que na maioria dos casos de suicídio estão presentes os transtornos mentais, principalmente depressão, transtorno do humor bipolar, dependência de álcool e de outras drogas psicoativas. Um estudo populacional revelou que, ao longo da vida, $17,1 \%$ das pessoas tiveram ideação suicida, $4,8 \%$ chegaram a elaborar um plano para tanto e $2,8 \%$ efetivamente tentaram o suicídio. E é com relação aos que efetivamente tentaram de alguma forma praticar o suicídio que se deve dar especial atenção, já esta é uma das principais estratégias de prevenção do suicídio ${ }^{6}$.

Além disso, insta destacar para os casos de mortes violentas, como no caso do suicídio, para o qual costuma ocorrer um complicador, ou seja, há um questionamento se aquela morte foi realmente suicídio ou se decorrente de um acidente ou um homicídio. Assim, para a determinação de um suicídio é preciso estabelecer se houve a intenção de morrer, o que nem sempre pode ser definido sem equívocos. Ademais, pode haver pressão de familiares para que se omita a natureza da morte na declaração de óbito 5 .

Ocorre que no Brasil uma larga proporção de mortes por causas externas tem o seu registro apenas o modo da morte, não a intenção. A exemplo tem-se as quedas e afogamentos, que representam 10,9\% de todas as mortes por causas externas. Ademais, outra proporção, em torno de $9 \%$, é registrada como morte com intenção indeterminada. Ou seja, tais registros costumam mascarar considerável proporção de casos de suicídios, principalmente entre adultos jovens de sexo masculino ${ }^{7}$.

Todavia, ainda que existam essas ressalvas, ainda assim o conjunto de dados populacionais aqui resumidos confirma a magnitude desse fenômeno envolvendo a humanidade, que para além do impacto emocional desse tipo de morte, há também o impacto em números. Isso, aliado à frequente associação de suicídios a transtornos mentais, levou a Organização da Saúde a fomentar ações de prevenção, trazendo o suicídio para a seara da saúde pública. Posto isso, ultrapassados os números e estatísticas, traremos à baila alguns mitos envolvendo o comportamento suicida.

- Mitos comuns sobre comportamento suicida

Há diversos mitos a respeito do comportamento suicida, mas que, na verdade, devem ser esclarecidos para que se evitem equívocos a respeito do tema. Alguns dos mitos mais comuns são ${ }^{7}$ :

Mito 1: "As pessoas que falam sobre o suicídio não farão mal a si próprias, pois querem apenas chamar a atenção. Isto é FALSO.” Todas as vezes que esse tipo de comentário for pronunciado, deve-se tomar todas as precauções necessárias, pois todo indivíduo que fale de ideação, de intenção ou de um plano suicida merece atenção especial. Todas as ameaças de se fazer mal devem ser levadas muito a sério.

Mito 2: "O suicídio é sempre impulsivo e acontece sem aviso. FALSO." Ainda que a grande maioria das pessoas pensem que morrer pelas suas próprias mãos pode parecer ter sido impulsivo, o suicídio pode ter sido ponderado durante algum tempo. Muitos indivíduos suicidas comunicam algum tipo de mensagem verbal ou comportamental sobre as suas ideações da intenção de se fazerem mal, basta que nos atentemos para estes tipos de sinais.

Mito 3: "Os indivíduos suicidas querem mesmo morrer ou estão decididos a matar-se. FALSO." A maioria das pessoas que se sentem suicidas dividem os seus pensamentos com pelo menos uma outra pessoa, podendo até mesmo ligarem para uma linha telefónica de emergência ou para um médico, o que constitui prova de ambivalência, e não de empenho em se matar.

Mito 4: "Quando um indivíduo mostra sinais de melhoria ou sobrevive a uma tentativa de suicídio, está fora de perigo. FALSO." Na verdade, um dos períodos mais perigosos e de maior atenção é imediatamente depois da crise, ou quando a pessoa está no hospital, na sequência de uma tentativa. Os dias seguintes depois da alta do hospital são um período durante o qual a pessoa está particularmente fragilizada e em perigo de se fazer mal. Como o comportamento passado pode influenciar o comportamento futuro, a pessoa com ideação e tentativa suicida muitas vezes continua em risco.

Mito 5: "O suicídio é sempre hereditário. FALSO." Afirmar que o suicídio teria causas hereditárias não é verdade, pois nem todos os suicídios podem ser associados à essa questão. Todavia, uma história familiar de suicídio, não deixa de ser um fator de risco importante para o comportamento suicida, particularmente em famílias onde a depressão é comum.

Mito 6: "Os indivíduos que tentam ou cometem suicídio têm sempre alguma perturbação mental. FALSO." Nos dias atuais há uma tendência de 
associar-se os comportamentos suicidas à depressão, ao abuso de substâncias, à esquizofrenia e outras perturbações mentais, além de comportamentos destrutivos e agressivos. Mas, esta associação não deve ser sobrestimada, já que a proporção relativa destas perturbações varia de lugar para lugar e há casos em que nenhuma perturbação mental foi detectada quando da ocorrência do ato suicida.

Mito 7: "Se um conselheiro falar com um cliente sobre suicídio, o conselheiro está a dar a ideia de suicídio à pessoa. FALSO." Quando um conselheiro ou qualquer profissional pergunta ao paciente sobre suicídio, não causa o comportamento suicida simplesmente por este ato. Na verdade, na medida em que se reconhece que o estado emocional do indivíduo é real, e tenta normalizar a situação induzida pelo stress, surgem os componentes necessários para a redução da ideação suicida.

Mito 8: "Após uma pessoa tentar cometer suicídio uma vez, nunca voltará a tentar novamente. FALSO." $\mathrm{Na}$ verdade, quando há tentativas de suicídio, as mesmas são tidas como um preditor crucial do suicídio.

Mito 9: "As crianças não cometem suicídio dado que não entendem que a morte é final e são cognitivamente incapazes de se empenhar num ato suicida. FALSO." Embora seja menos comum, as crianças cometem suicídio e, qualquer gesto, em qualquer idade, deve ser levado muito seriamente, pois muitos não sabem expressar o que sentem, apenas demonstram através de atos e comportamentos.

Diante dessas concepções errôneas acerca do suicídio, algumas pessoas podem sentir-se ansiosas ou mal preparadas para trabalhar com indivíduos suicidas e, para tanto, devem desenvolver competências de aconselhamento que sejam eficazes, para que possam lidar com esta população. É crucial que o conselheiro ou profissional seja plenamente consciente dos fatores de risco e compreenda essas situações.E quais seriam os possíveis grupos de risco e os sinais de um comportamento suicida?

\section{- Grupos de risco e sinais do comportamento suicida}

Quem está em risco? Estão em risco os indivíduos que apresentam históricos de tentativas de suicídio ou autoagressão, como a automutilação; aqueles que sofrem bullying, incluindo nestes o sentimento de menos-valia frente aos demais colegas, por não terem a mesma produtividade ou capacidade de acompanhar o conteúdo escolar, assim como a pressão pelo alto rendimento, por vezes acompanhado de ameaças e perseguições; situações atuais ou anteriores de violência intra ou extrafamiliar; histórico de abuso sexual; suicídio na família; baixa autoestima; usuários de álcool ou outras drogas; histórico de transtorno mental; populações mais vulneráveis a pressões sociais e discriminação ${ }^{8}$.
Ademais, podem ser elencados alguns outros fatores de risco, como experiência de perda, solidão, rompimento de um relacionamento, problemas financeiros, dores e doenças crônicas, violência, abuso, conflito ou outras emergências humanitárias. Mas, o fator de risco mais forte para suicídio é uma tentativa anterior de suicídio". Com relação aos transtornos mentais, embora a ligação entre suicídio e os mesmos esteja bem estabelecida, muitos suicídios acontecem impulsivamente em momentos de crise. Dentre os transtornos mentais mais comumente associados ao suicídio, podemos elencar: depressão, transtorno do humor bipolar, dependência de álcool e de outras drogas psicoativas. Esquizofrenia e certas características de personalidade, que também são importantes fatores de risco. E, se mais de uma dessas condições combinarem-se, a situação de risco tende a agravar-se, como por exemplo: depressão e alcoolismo; ou ainda, quando há a coexistência de depressão, ansiedade e agitação ${ }^{10}$.

Todavia, não se trata de afirmar que todo suicídio tenha relação com alguma doença mental, nem que toda pessoa acometida por uma doença mental irá cometer suicídio, mas não se pode excluir a constatação de que uma doença mental é um importante fator de risco para o suicídio. A causa de um suicídio, chamado de fator predisponente, é muito mais complexa do que um acontecimento recente, como a perda do emprego ou um rompimento amoroso, denominados de fatores precipitantes ${ }^{10}$.

O que se deve atentar é para o fato de que o risco de suicídio aumenta mais de 20 vezes em indivíduos com episódio depressivo maior, e é ainda maior em sujeitos com comorbidade com outros transtornos psiquiátricos ou doenças clínicas. Dados de autópsia psicológica mostram que aproximadamente metade dos indivíduos que faleceram por suicídio estava sofrendo de depressão. Diagnóstico precoce e tratamento correto da depressão são, comprovadamente, uma das maneiras mais eficazes de se prevenir suicídio ${ }^{11}$.

Assim, o risco é maior na vigência da doença e de comorbidades. O risco é menor quando a doença é tratada ou está em remissão ${ }^{12}$. Nesse aspecto, importante atentarmos para algumas questões relevantes a despeito da depressão, doença mental tão recorrente nos últimos tempos. A palavra depressão é utilizada de maneira equivocada, como sendo um estado de humor, uma tristeza diante de algum acontecimento ou frustração. Todavia, ela é além de um estado de humor ou uma tristeza passageira, pode ser definida e entendida como sendo uma tristeza profunda e prolongada. Os relatos a despeito dos sintomas são diversos, podendo ser identificados como sendo um cansaço de viver, um não gostar da vida e o que ela proporciona, uma não aceitação da sua realidade em nível pessoal, uma dor provinda da alma, uma amargura sem limites, uma vida sem vida, 
um vazio sem limites, um estado de tristeza sem qualquer perspectiva futura ${ }^{13}$.

A depressão pode ser graduada de leve a severo. Não é uma doença nova, relatos apontam que ela é tão antiga quanto o homem. A Bíblia a reconhece nas passagens de Jó, Pedro e Judas. O primeiro, Jó, era portador de uma revolta e amargura; o segundo, Pedro, quando negou Jesus sentiu a culpa, o arrependimento e o remorso, fatores comuns nos estados depressivos. Por fim, Judas, que ao trair Jesus, foi acometido por uma reação depressiva aguda, decorrente de um intenso sentimento de culpa e remorso, o que culminou em seu suicídio ${ }^{13}$. A depressão pode se manifestar em qualquer indivíduo, mas, no entanto, existem pessoas com maior predisposição à depressão, são aquelas pessoas sisudas, com pouco senso de humor, que não suportam bem as frustrações, críticas ou rejeições, que guardam sentimentos de raiva e ódio, portadoras de preocupações exageradas ${ }^{13}$.

Além desses fatores, o modo de viver, as frustrações, a família, o trabalho, as constrições de ordem moral e econômica podem ser determinantes de comportamentos doentios, como a depressão e ansiedade. Todavia, referidas condições sociais, por si só, não explicam um suicídio. As pessoas que cometeram o ato suicida e que se encontravam numa dessas condições, frequentemente tinham um transtorno mental subjacente, aumentando assim a vulnerabilidade ao suicídio. O que ocorre é que muitas vezes os transtornos mentais não são detectados ou não são adequadamente tratados. Faltam informações a esse respeito, tais como: saber reconhecer uma doença mental, quais os tratamentos disponíveis, sua efetividade e local em que pode ser obtido apoio emocional ${ }^{10}$.

Além dessas questões, verificam-se altas taxas de suicídio também entre os grupos vulneráveis e que sofrem discriminação, tais como os refugiados e os migrantes. Também podem ser incluídos os indígenas, lésbicas, gays, bissexuais, transgêneros, intersexuais (LGBTI), bem como os prisioneiros e negros $^{14}$. Entre os indivíduos em risco podem ser incluídos os adolescentes, que correm um risco muito alto de se machucar e de se suicidar. O suicídio e a morte acidental por danos pessoais foram a terceira causa de mortalidade de adolescentes no ano de 2015, o que resultou em uma estimativa de 67.000 mortes. Nessa abordagem, importante atentarmos para a automutilação, que ocorre em grande parte entre os adolescentes mais velhos e, no mundo todo, é a segunda principal causa de morte entre as adolescentes mais velhas. Na Europa e no Sudeste Asiático é a principal ou segunda causa de morte entre os adolescentes ${ }^{15}$.

Históricos de abuso de álcool e drogas também estão presentes em muitas crianças e adolescentes que cometeram o suicídio. Um em cada quatro pacientes suicidas consumiu álcool ou droga antes do ato. Ainda entre os jovens, podem ser citados os transtornos alimentares, pois nessa idade a insatisfação com o corpo entre crianças $e$ adolescentes é muito grande, eles tentam perdem peso e ficam preocupados com o que devem ou não comer, com o julgamento das outras pessoas. Entre as meninas o risco ainda é maior, principalmente entre aquelas que sofrem algum tipo de anorexia, pois meninas anoréticas frequentemente sofrem de depressão, sendo o risco de suicídio para esse grupo 20 vezes maior que em relação a população jovem em geral, sem exclusão dos meninos, que também podem sofrer algum transtorno alimentar ${ }^{17}$.

Outros fatores desenvolvimentais não diretamente incluídos nos critérios diagnósticos de quadros psicopatológicos têm sido investigados em casos de suicídio. Entre outras características, a identificação destes fatores possibilita estratégias de prevenção primária. São dimensões implicados no suicídio: história de abuso sexual na infância, associada a um comportamento suicida posterior; a presença de abuso físico que também se associa ao incremento no risco de comportamento suicida, mas com intensidade menor. Por exemplo, o aumento de chance de tentativa de suicídio única em homens foi de $\mathrm{OR}=2,3$ (CI 95\% 1,1-4,8) em indivíduos com abuso físico, e de OR = 6,8 (CI 95\% 2,0-23,3) em sujeitos com história de abuso sexual. Já, indivíduos com história de abuso combinado (físico e sexual) apresentaram ORs ainda mais elevados ${ }^{12}$. Nesse contexto podemos destacar para o fato de que padrões familiares destrutivos e eventos traumáticos no início da infância afetam a vida posteriormente, principalmente se houve alguma dificuldade em lidar com o trauma.

Além do exposto, alguns outros aspectos relacionados com a disfunção e a instabilidade familiar e eventos de vida negativos descobertos em crianças e adolescentes suicidas podem ser observados, tais como: psicopatologia dos pais, com a presença de transtornos afetivos e outros transtornos psiquiátricos, abuso e álcool e outras substâncias ou comportamento antissocial da família, história de suicídio ou tentativa na família, abuso e violência familiar, cuidado insuficiente proveniente de pais/guardiães com pouca comunicação entre os entes da família, brigas familiares, autoridade excessiva ou inadequada dos pais/guardiães, falta de tempo desse últimos para observar e lidar com o estresse emocional das crianças, o que cria uma atmosfera de rejeição e negligência, rigidez familiar e até mesmo família adotiva ${ }^{17}$.

Salienta-se que esses padrões familiares acima declinados estão vinculados, mas não sempre, aos casos de crianças e adolescentes que tentaram ou cometeram suicídio. Algumas evidências sugerem que pessoas jovens suicidas provêm, frequentemente, 
de famílias com mais de um problema, e em sendo assim, os riscos apresentam-se de maneira cumulativa. Muitas das vezes há resistência em procurar ajuda por parte desses jovens, devido a uma postura de lealdade perante os pais, ou por não desejarem procurar ajuda, ou por serem proibidos de revelar os segredos e padrões familiares a que estão vinculados ${ }^{17}$.

E como identificar os sinais, sobretudo em crianças e adolescentes? Necessário trazer à baila alguns sinais de alerta para um comportamento suicida entre os jovens e crianças, tais como: a existência de preocupação com a sua própria morte ou falta de esperança; expressão de ideias ou de intenções suicidas; diminuição ou ausência de autocuidado; mudanças na alimentação e/ou hábitos de sono; uso abusivo de drogas e álcool; alterações nos níveis de atividade ou de humor; crescente isolamento de amigos/família; diminuição do rendimento escolar; autoagressão, o que leva muitas vezes a mudanças na forma de se vestir para cobrir determinadas partes do corpo, como por exemplo, o uso de blusas de manga comprida e, como decorrência desse processo auto lesivo, a relutância em participar de atividades físicas que antes eram apreciadas, em especial aquelas em que se utilizam shorts ou roupas de banho ${ }^{8}$.

Posto isso, é necessária a atenção aos sinais sutis de uma criança ou um adolescente, pois podem estar necessitando de ajuda. Existem algumas orientações para que se possa conversar sobre um comportamento suicida, notadamente entre as crianças e adolescentes ${ }^{7}$. Tratar com seriedade o que é dito; agir com respeito, sempre se colocando no lugar do outro, transmitindo ao outro que se importa com ele e que está disposto a auxiliá-lo; adotar uma abordagem sem julgamento, entendendo que $o$ comportamento de uma criança ou adolescente pode ser a única forma encontrada para lidar com a situação em que se encontra; certificar-se que a criança ou adolescente compreende os limites da confidencialidade, já que se estiver em risco de prejudicar a si próprio ou aos outros, a confidencialidade não pode ser mantida; ouvir de maneira calma e pacienciosa; ter olhos, ouvidos e linguagem corporal abertos ao que a criança ou adolescente tem a dizer, sem julgamentos ou mostrar choque diante das colocações; mostrar à criança ou ao adolescente que ele será ouvido, oferecendo apoio, se necessário, buscando ajuda de outros profissionais ou serviços.

Em alguns casos, aquele que acolhe poderá encorajar a criança ou adolescente a conversar com amigos, pais e outros adultos de confiança sobre seus pensamentos e sentimentos, em outras circunstâncias, é necessário buscar apoio adicional. Nesse contexto, a família pode ser o maior aliado ao profissional, pois pode fornecer informações a respeito do caso, trazendo melhor compreensão, formando assim uma aliança com o profissional.

\section{CONSIDERAÇÕES FINAIS}

Feitas tais abordagens, em relação aos fatores de risco de um comportamento suicida, podem-se elencar alguns principais, tais como: experiência de perda, solidão, rompimento de um relacionamento, problemas financeiros, dores e doenças crônicas, violência, abuso, conflito ou outras emergências humanitárias. Mas, o fator de risco mais forte para suicídio é uma tentativa anterior de suicídio ${ }^{9}$. No que tange aos transtornos mentais, embora a ligação entre suicídio e os mesmos esteja bem estabelecida, muitos suicídios acontecem impulsivamente em momentos de crise. Dentre os transtornos mentais mais comumente associados ao suicídio temos a depressão, o transtorno do humor bipolar, dependência de álcool e de outras drogas psicoativas. Todavia, não se trata de afirmar que todo suicídio tenha relação com alguma doença mental, nem que toda pessoa acometida por uma doença mental irá cometer suicídio, mas não se pode excluir a constatação de que uma doença mental é um importante fator de risco para o suicídio. Quanto aos sinais de um comportamento suicida, sobretudo em crianças e adolescentes, tem-se que os mesmos são comumente verificados quando há a presença de uma preocupação por parte desses jovens com a sua própria morte ou falta de esperança; expressão de ideias ou de intenções suicidas; diminuição ou ausência de autocuidado; mudanças na alimentação e/ou hábitos de sono; uso abusivo de drogas e álcool; alterações nos níveis de atividade ou de humor; crescente isolamento de amigos/família; diminuição do rendimento escolar; autoagressão, o que leva muitas vezes a mudanças na forma de se vestir para cobrir determinadas partes do corpo ${ }^{8}$.

Verificada a ocorrência de tais sinais, é de suma importância que a família esteja engajada no processo de ajuda e escuta ao jovem em sofrimento, contando sempre com o auxílio de profissionais da área, deixando de lado estigmas e mitos populares, já que os suicídios são evitáveis, bastando para isso que nos atentemos para os sinais e para os grupos de risco.

\section{REFERÊNCIAS}

1. Durkheim É. O Suicídio. estudo de Sociologia. São Paulo: Martins Fontes; 2000.

2. WHO. World Health Organization. Mental health. Geneva; 2016. Disponível em: <https://www.who.int/mental_health/prevention/suicid e/suicideprevent/en/>. Acesso em: 12 jan. 2020.

3. WHO. World Health Organization. Geneva; 2016. Disponível em: <https://www.who.int/mental_health/suicideprevention/Global_AS_suicide_rates_bothsexes_2016. png>. Acesso em: 12 jan. 2020. 
4. Suicídio vira epidemia de extensão global, diz OMS. Gazeta do Povo, 04 set. 2014. Disponível em: <https://www.gazetadopovo.com.br/vida-ecidadania/suicidio-vira-epidemia-de-extensaoglobal-diz-oms-ed22rk3jixa24qo1hxpsueij2/>. Acesso em: 12 jan. 2020.

5. Brasil. Ministério da Mulher, da Família e dos Direitos Humanos. O suicídio e a automutilação tratados sob a perspectiva da família e do sentido da vida. 2019. p. 1-42.

6. Botega NJ. Comportamento suicida: epidemiologia. Psicologia USP. 2014;25(3):231-36.

7. OMS. Organização Mundial de Saúde. Prevenção do suicídio um recurso para conselheiros. Departamento de Saúde Mental e de Abuso de Substâncias. Gestão de Perturbações Mentais e de Doenças do Sistema Nervoso. Genebra; 2006, p. 9 $-11$.

8. Guia Intersetorial de Prevenção do Comportamento Suicida em Crianças E Adolescentes; 2019.

9. WHO. World Health Organization. Suicide prevention. Geneva; 2019. Disponível em: < https://www.who.int/health-

topics/suicide\#tab=tab_2>. Acesso em: 12 jan. 2020.

10. ABP. Associação Brasileira de Psiquiatria. Comportamento suicida: conhecer para prevenir, dirigido para profissionais de imprensa. [on-line], 2009. Disponível em: <www.fundacaobunge. org.br/uploads>. Acesso em: 12 jan 2020.

11. Botega NJ, Welang BSG, Cais CFS, Macedo MMK. Prevenção do comportamento suicida. Psico (Porto Alegre). 2006;37(3):213-20.

12. Chachamovich E, Stefanello S, Botega N, Turecki G. Quais são os recentes achados clínicos sobre a associação entre depressão e suicídio? Rev Bras Psiquiatr.2009;31(Suppl 1):S18-25.

13. Condotta JL. Ansiedade, pânico e depressão : visão médico-psicológica e visão espírita. Matão: Clarim; 2017.

14. WHO. World Health Organization. Suicide. Geneva; 2019. Disponível em: <https://www.who.int/news-room/factsheets/detail/suicide>. Acesso em: 13 jan. 2020.

15. WHO. World Health Organization. More than 1.2 million adolescents die every year, nearly all preventable. Geneva; 2017. Disponível em: <https://www.who.int/news-room/detail/16-052017-more-than-1-2-million-adolescents-dieevery-year-nearly-all-preventable>. Acesso em: 13 jan. 2020.

\section{CONFLITO DE INTERESSES}

Os autores declaram não haver conflitos de interesse.

\section{AUTOR PARA CORRESPONDÊNCIA}

\section{Camila Mazza da Silva}

camazzasilva@gmail.com
Submetido em 24/04/2020

Aceito em 06/07/2020 